\title{
Narasi Nilai Kepemimpinan Astha Brata Dalam Manajemen Kepemimpinan Kepala Sekolah Pada Sekolah Pinggiran
}

\author{
Angga Prasetiya \\ Universitas Sebelas Maret \\ anggaprasetiya666@gmail.com
}

\section{Article History}

received $1 / 9 / 2021$

\begin{abstract}
The term suburban school emerged as a result of the polarization between schools located in cities and suburban areas. Negative stigma is often attached to suburban schools, with all their limitations. Therefore, the skills of the principal as a leader are highly demanded in school administration in order to create a golden generation in 2045. The eight values of Astha Brata's leadership are ideal values that must be possessed by a leader. The actualization of Astha Brata's leadership values by the principal in suburban schools is absolutely necessary, because of the peculiarities of the problem. This study describes the form of actualization of Astha Brata's values on the leadership management of the principal at a suburban school in Central Aceh. Data collection techniques come from written sources such as books, as well as scientific articles, as well as photos from documentation of school activities. The form of actualization is analyzed based on the problem and the solution to the problem is proven by school documentation in the form of photographs, so that an overview of the actualization of the value of Astha Brata's leadership in the leadership management of school principals in suburban schools can be comprehensively summarized.
\end{abstract}

Keywords: Astha Brata, leadership, principal, suburban school

\begin{abstract}
Abstrak
Istilah sekolah pinggiran muncul sebagai akibat polarisasi antara sekolah yang terletak di kota dan daerah pinggiran. Stigma negatif seringkali dilekatkan kepada sekolah pinggiran, dengan segala keterbatasannya. Oleh karena itu, kecakapan kepala sekolah sebagai pemimpin sangat dituntut dalam penyelenggaraan sekolah guna mencetak generasi emas di tahuh 2045. Delapan nilai kepemimpinan Astha Brata merupakan nilai ideal yang harus dimiliki oleh seorang pemimpin. Aktualisasi nilai kepemimpinan Astha Brata oleh kepala sekolah pada sekolah pinggiran adalah hal sangat mutlak diperlukan, karena kekhasan permasalahannya. Penelitian ini mendeskripsikan bentuk aktualisasi nilai-nilai Astha Brata terhadap manajemen kepemimpinan kepala sekolah pada salah satu sekolah pinggiran yang berada di Aceh Tengah. Teknik pengumpulan data berasal dari sumber tertulis seperti buku, maupun artikel ilmiah, juga foto-foto dari dokumentasi kegiatan sekolah. Bentuk aktualisasi dianalisis berdasarkan permasalahan dan pemecahan permasalahannya dibuktikan dengan dokumentasi sekolah berupa foto-foto, sehingga gambaran tentang aktualisasi nilai kepemimpinan Astha Brata dalam manajemen kepemimpinan kepala sekolah pada sekolah pinggiran dapat dirangkum secara komprehensif.
\end{abstract}

Kata kunci: Astha Brata, kepemimpinan, kepala sekolah,Sekolah Pinggiran

Social, Humanities, and Education Studies (SHEs): Conference Series https://jurnal.uns.ac.id/shes

p-ISSN 2620-9284

e-ISSN 2620-9292 


\section{PENDAHULUAN}

Dikotomi antara sekolah yang terletak di kota dan sekolah yang terletak di pinggiran kota, ternyata berimplikasi bagaimana cara pandang terhadap keduanya. Sekolah kota lebih dikenal sebagai sekolah unggulan, sedangkan sekolah pinggiran terkesan sebagai sekolah buangan. Stereotipe seperti itu didasari oleh kondisi sekolah pinggiran yang serba dalam keterbatasannya. Kendati demikian, juga tidak tepat mengatakan sekolah pinggiran sebagai sekolah buangan. Jenis Permasalahaan di sekolah kota dan pinggiran tentu berbeda, permasalahan yang khas dalam sekolah pinggiran antara lain tingkat ekonomi yang rentan miskin, tenaga pengajar yang tidak tercukupi, dan sarana pra-sarana pembelajaran yang seringkali tidak mendukung.

Perbedaan permasalahan yang dialami sekolah kota dan sekolah pinggiran, tentu menuntut penyelesaian permasalahan yang berbeda pula. Untuk itu pada sekolah pinggiran, dibutuhkan seorang kepala sekolah yang tidak hanya sekedar menyandang jabatan strategis, namun harus bertanggung jawab dalam mengembangkan sekolah (Sastramayani dan Badarwan, 2019). kepala sekolah harus memiliki keterampilan memimpin yang cakap untuk mengelola sumber daya yang terdapat di sekolahnya (Sudarmiati, 2020).

Kepemimpinan di sekolah pinggiran seringkali bersifat stagnan, karena kepala sekolah berupaya sedemikian mungkin untuk mempertahankan status quo yang ada pada sekolah tersebut. akibatnya sinergi antara kepala sekolah, guru, siswa, dan masyarakat setempat tidak terjalin dengan baik, padahal seorang pemimpin bukan sekedar otoritas formal belaka, ia harus mengutamakan kemajuan sebagai suatu proses dalam kepemimpinannya (Ahmad, 2019).

Kecakapan kepemimpinan kepala sekolah pada daerah pinggiran, dapat mengacu kepada delapan nilai kepemimpinan Astha Brata yang secara operasional, nilai-nilai luhur kepemimpinan di dalamnya mengandung makna (Sastrawan,2019); Surya (Matahari) yang berarti adil dan mengutamakan musyawarah dalam penyelesaian permasalahan, Bayu (Angin) memperhatikan bawahan, Candra (Bulan) pemaaf, dan menyenangkan bawahan, Brama (Api) tegas dalam memberikan perintah, Kuwera (Bumi) tidak pilih kasih terhadap bawahan, Endra (Hujan) memberi hal positif terhadap bawahan, Baruna (Laut) teguh pada prinsip, Yama (Maut) tegas menghukum yang salah.

Untuk melihat bagaimana relevansi nilai Astha Brata yang diaktualisasikan pada sekolah pinggiran, maka perlu untuk menetapkan satu objek dari aktualisasi nilai kepemimpinan tersebut. objek yang dikaji adalah manajemen kepemimpinan Kepala Sekolah SMA Negeri 19 Takengon. sekolah yang digolongkan sebagai sekolah pinggiran karena letaknya cukup jauh dari Kota Takengon. Terletak di Desa Pantan Tengah Kecamatan Rusip Antara, Aceh Tengah. Sekolah tersebut juga memiliki satu kelas jauh di Desa Pameue, yang berjarak 47,3 km dari Kota Takengon dan dalam tiga tahun belakangan, tidak terdapat sekolah tingkat SMA berstatus negeri di desa tersebut. Deskripsi bentuk aktualisasi nilai Astha Brata pada SMA Negeri 19 Takengon, akan menjadi penggambaran penting bagi kita dalam melihat permasalahanpermasalahan khas yang terjadi pada daerah pinggiran.

\section{METODE}

Penulisan karya ini berfokus mendeskripsikan nilai-nilai kepemimpinan dalam Astha Brata dan aktualisasinya terhadap manajemen kepemimpinan kepala sekolah di SMA Negeri 19 Takengon. Oleh karena itu penulisan karya ini menggunakan metode penelitian kualitatif yang menurut Cresswell (2008) adalah suatu pendekatan atau penelusuran untuk mengeksplorasi dan memahami suatu gejala sentral. Juga menurut Albi Anggito dan Johan Setiawan (2018), bahwa penelitian kualitatif adalah 
pengumpulan data dalam suatu latar alamiah untuk mengetahui sebuah fenomena. Penulisan karya ini terdiri atas dua tahap, tahapan yang pertama berupa eksplorasi nilai-nilai Astha Brata dalam sumber-sumber tertulis, dan tahapan yang kedua mendeskripsikan aktualisasi nilai-nilai kepemimpinan Astha Brata pada manajemen kepemimpinan kepala sekolah SMA Negeri 19 Takengon yang dibuktikan dengan dokumentasi berupa foto-foto.

\section{HASIL DAN PEMBAHASAN}

Eksplorasi nilai-nilai kepemimpinan Astha Brata

Kepemimpinan sendiri diartikan sebagai kemampuan seseorang untuk mempengaruhi, dan dengan segala otoritas yang dimilikinya mampu menggerakkan orang lain sesuai dengan perintahnya (Ahmad,2019). Artinya kepemimpinan adalah manajemen hubungan antara pemimpin dan yang dipimpin. Oleh karena itu dalam kehidupan ini, manusia selalu membutuhkan seorang pemimpin (Silawati dan Sukmawati, 2021). Kendati demikian, banyaknya teori kepemimpinan yang ada pada masa sekarang, seperti Teori Kepemimpinan Transformational dan Kepemimpinan Skill (Lumban Gaol, 2020). Kita telah memiliki sebuah model kepemimpinan dari Jawa yang bernama Astha Brata.

Secara etimologis kata Astha berarti delapan, dan Brata yang berarti pedoman (Suyami, 2008). Dalam Serat Rama, dikisahkan bahwa Astha Brata merupakan isi nasihat yang diberikan oleh Rama Wijaya kepada Wibisana yang akan menggantikan kakaknya Rahwana menjadi Raja Alengka (As'ad, Wahyu, Mariana,2011). Dalam kisah Mahabarata, Astha Brata juga terdapat pada lakon-lakon wayang, seperti Wahyu Makutharama yang menceritakan diterimanya wahyu tentang kepemimpinan Rama Wijaya oleh Arjuna. Lakon ini disebut dengan Rama Nitik (Suwardi, 2013).

Astha Brata pada dasarnya merupakan simbolisasi kepemimpinan dewa-dewa dalam tradisi agama Hindu. Simbolisasi tersebut diadopsi dari interpretasi sifat-sifat alam seperti; matahari, agin, bulan, api, bumi, hujan, laut, maut. Keseluruhan makna simbolisasi adalah bentuk ideal yang harus menjadi pedoman perilaku seorang pemimpin. Nilai Astha Brata terdapat dalam bentuk-bentuk karya sastra seperti Serat Rama, Manawa Dharmacastra, Serat Nitisruti, Serat Putakaraja Purwa. Dalam kisah perwayangan terutama dalam lakon Makutha Rama, internalisasi nilai-nilai Astha Brata sering dipentaskan, sehingga Astha Brata sangat melekat dalam masyarakat Jawa.

Tafsiran sifat-sifat dewa tersebut dalam berbagai karya Sastra Jawa, berimplikasi kepada beragamnya makna tentang nilai-nilai Astha Brata itu sendiri. Menurut I Nyoman Surpa Adisastra (2021), Astha Brata adalah penggambaran sifat dewa yang terdiri atas 1) Indra Brata Bernilai Kesejahteraan, pemimpin harus memberikan kesejahteraan untuk rakyatnya, 2) Vayu Brata Bernilai Kewaspadaan dan Kebugaran, pemimpin harus memiliki kewaspadaan dan menjamin kesehatan warganya, 3) Yama Brata Bernilai Hukum dan Keadilan, pemimpin harus menegakkan hukum secara adil, 4) Surya Brata Bernilai Kepedulian, pemimpin harus memiliki kepedulian untuk rakyatmya, 5) Agni Brata Bernilai Kecerdasan dan Keberanian, pemimpin harus cerdas dan berani dalam menegakkan kebenaran, 6) Varuna Brata Bernilai Pelindung, pemimpin harus melindungi rakyatnya, 7) Candra Brata Bernilai Etika dan Susila, pemimpin harus memiliki sifat luhur sebagai panutan rakyatnya, 8) Kubera Brata Bernilai Kemakmuran, pemimpin harus memberikan kemakmuran bagi rakyatnya.

Delapan Nilai kepemimpinan Astha Brata (Suwardi,2013) yang harus dimiliki seorang pemimpin adalah 1) Laku hambeging candra, seorang pemimpin harus menjadi penerang yang menyejukan rakyatnya. 2) Laku hambeging dahana, seorang pemimpin harus tegas seperti api yang membakar. 3) Laku hambeging kartika, ibarat bintang-bintang di angkasa seorang pemimpin harus memiliki rasa percaya diri. 4) Laku hambeging kisma, pemimpin harus memiliki sifat, berbelas kasih dengan 
siapapun bahkan orang yang membencinya. 5) Laku hambeging samirana, seoarang pemimpin dituntut memiliki ketellitian. 6) Laku hambeging samodra, seorang pemimpin harus memiliki sifat pemaaf. 7) Laku hambeging surya, seorang pemimpin harus memberi inspirasi kepada bawahannya. 8) Laku hambeging tirta, pemimpin harus bersifat adil seperti permukaan air yang rata.

Tabel 1 komparasi versi Astha Brata (As'ad, Wahyu, Mariana, 2011)

\begin{tabular}{|c|c|c|c|}
\hline $\begin{array}{c}\text { Manawa } \\
\text { Darmachastra }\end{array}$ & Serat Rama & $\begin{array}{c}\text { Serat } \\
\text { Nitistruti }\end{array}$ & $\begin{array}{c}\text { Serat } \\
\text { Pustakaraja } \\
\text { Purwa }\end{array}$ \\
\hline
\end{tabular}

\begin{tabular}{|c|c|c|c|c|}
\hline $\begin{array}{l}\text { Surya } \\
\text { (matahari) }\end{array}$ & $\begin{array}{l}\text { Surya } \\
\text { (matahari) }\end{array}$ & $\begin{array}{l}\text { Surya } \\
\text { (matahari) }\end{array}$ & $\begin{array}{l}\text { Watak Surya } \\
\text { (matahari) }\end{array}$ & $\begin{array}{l}\text { Laku Surya } \\
\text { (matahari) }\end{array}$ \\
\hline $\begin{array}{l}\text { Mampu } \\
\text { mengubah } \\
\text { secara } \\
\text { perlahan }\end{array}$ & $\begin{array}{l}\text { Adil, } \\
\text { bermusyawara } \\
\text { h, } \\
\text { tanpa } \\
\text { konfrontasi } \\
\text { kekerasan }\end{array}$ & $\begin{array}{l}\text { Membimbing } \\
\text { pengikut } \\
\text { dengan } \\
\text { sabar, tanpa } \\
\text { konfrontasi } \\
\text { keras }\end{array}$ & $\begin{array}{l}\text { Perlahanlahan/ } \\
\text { berhati-hati } \\
\text { dalam } \\
\text { mempengaruhi }\end{array}$ & $\begin{array}{l}\text { Mampu } \\
\text { memberi } \\
\text { inspirasi }\end{array}$ \\
\hline $\begin{array}{l}\text { Wayu (angin) } \\
\text { Turun } \\
\text { langsung } \\
\text { mengawasi } \\
\text { pengikut }\end{array}$ & $\begin{array}{l}\text { Bayu (angin) } \\
\text { Teliti, } \\
\text { memperhatika } \\
\text { n } \\
\text { pengikut }\end{array}$ & $\begin{array}{l}\text { Bayu (angin) } \\
\text { Kaya ilmu, } \\
\text { teliti, } \\
\text { mengawasi } \\
\text { pengikut }\end{array}$ & $\begin{array}{l}\text { Watak } \\
\text { Samirana } \\
\text { (angin) } \\
\text { Meneliti dan } \\
\text { memeriksa } \\
\text { tingkah laku } \\
\text { pengikut }\end{array}$ & $\begin{array}{l}\text { Laku Samirana } \\
\text { (angin) } \\
\text { Berjiwa teliti }\end{array}$ \\
\hline $\begin{array}{l}\text { Candra (bulan) } \\
\text { Pribadi } \\
\text { periang/ } \\
\text { menyenangka } \\
\text { n } \\
\text { pengikut }\end{array}$ & $\begin{array}{l}\text { Candra (bulan) } \\
\text { Pemaaf, } \\
\text { periang, } \\
\text { menyenangka } \\
\text { n } \\
\text { pengikut }\end{array}$ & $\begin{array}{l}\text { Candra } \\
\text { (bulan) } \\
\text { Adil, } \\
\text { menyenangk } \\
\text { an } \\
\text { hati pengikut, } \\
\text { periang }\end{array}$ & $\begin{array}{l}\text { Watak } \\
\text { Rembulan } \\
\text { (bulan) } \\
\text { Periang, } \\
\text { menyenangka } \\
\mathrm{n} \\
\text { pengikut }\end{array}$ & $\begin{array}{l}\text { Pengikut } \\
\text { Laku Candra } \\
\text { (bulan) } \\
\text { Memberi } \\
\text { penerangan, } \\
\text { menyenangka } \\
\mathrm{n} \\
\text { pengikut }\end{array}$ \\
\hline $\begin{array}{l}\text { Agni (api) } \\
\text { Bersemangat, } \\
\text { berani } \\
\text { menyingkirkan } \\
\text { keburukan }\end{array}$ & $\begin{array}{l}\text { Brama (api) } \\
\text { Bergerak/men } \\
\text { ggerakkan } \\
\text { pengikut }\end{array}$ & $\begin{array}{l}\text { Brama (api) } \\
\text { Bersemangat } \\
\text { berani } \\
\text { menghilangk } \\
\text { an } \\
\text { keburukan }\end{array}$ & $\begin{array}{l}\text { Watak Agni } \\
\text { (api) } \\
\text { Menghukum } \\
\text { yang } \\
\text { bersalah }\end{array}$ & $\begin{array}{l}\text { Laku Dahana } \\
\text { (api) } \\
\text { Tegas, } \\
\text { Menghukum } \\
\text { yang bersalah }\end{array}$ \\
\hline $\begin{array}{l}\text { Prithiwi (bumi) } \\
\text { Adil, } \\
\text { berperilaku } \\
\text { sama terhadap } \\
\text { pengikut }\end{array}$ & $\begin{array}{l}\text { Kuwera (bumi) } \\
\text { Adil, } \\
\text { dipercaya, } \\
\text { tidak pilih } \\
\text { kasih } \\
\text { pada pengikut }\end{array}$ & 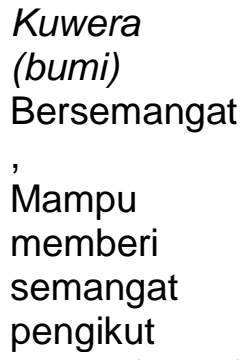 & $\begin{array}{l}\text { Watak Bumi } \\
\text { Murah hati }\end{array}$ & $\begin{array}{l}\text { Laku Kisma } \\
\text { (Bumi) } \\
\text { Murah hati, } \\
\text { kaya, } \\
\text { suka berderma }\end{array}$ \\
\hline Indra & ujan) & Endra (hujan) & Watak Tirta & aku Tir \\
\hline
\end{tabular}


SHEs: Conference Series 5 (1) (2022) 24- 35

\begin{tabular}{|c|c|c|c|c|}
\hline $\begin{array}{l}\text { (badai/hujan) } \\
\text { Memberi } \\
\text { keuntungan } \\
\text { bersama }\end{array}$ & $\begin{array}{l}\text { Memberi } \\
\text { keuntungan/de } \\
\text { rma/nilai } \\
\text { tambah } \\
\text { bagi semua } \\
\text { pengikut }\end{array}$ & $\begin{array}{l}\text { Sopan } \\
\text { santun } \\
\text { kepada } \\
\text { pengikut }\end{array}$ & $\begin{array}{l}\text { (air) } \\
\text { Pemaaf, } \\
\text { memulihkan } \\
\text { keadaan }\end{array}$ & $\begin{array}{l}\text { Adil, tidak pilih } \\
\text { kasih }\end{array}$ \\
\hline $\begin{array}{l}\text { Waruna (laut) } \\
\text { Disegani, } \\
\text { menghukum } \\
\text { pengikut yang } \\
\text { bersalah }\end{array}$ & $\begin{array}{l}\text { Baruna (laut) } \\
\text { Berpendirian } \\
\text { teguh pada } \\
\text { prinsip }\end{array}$ & $\begin{array}{l}\text { Baruna (laut) } \\
\text { Berani } \\
\text { menghadapi } \\
\text { masalah, } \\
\text { menghimpun } \\
\text { pengetahuan } \\
\text { / belajar }\end{array}$ & $\begin{array}{l}\text { Watak } \\
\text { Mendung } \\
\text { (awan/langit) } \\
\text { Adil, tidak pilih } \\
\text { kasih pada } \\
\text { pengikut }\end{array}$ & $\begin{array}{l}\text { Laku Samodra } \\
\text { (laut) } \\
\text { Pemaaf, } \\
\text { penampung } \\
\text { aspirasi } \\
\text { pengikut }\end{array}$ \\
\hline $\begin{array}{l}\text { Yama (maut) } \\
\text { Mampu } \\
\text { menguasai } \\
\text { semua } \\
\text { pengikut }\end{array}$ & $\begin{array}{l}\text { Yama (maut) } \\
\text { Tegas, berani, } \\
\text { menghukum } \\
\text { yang } \\
\text { salah, } \\
\text { membersihkan } \\
\text { keadaan buruk }\end{array}$ & $\begin{array}{l}\text { Yama (maut) } \\
\text { Tegas, } \\
\text { memberi } \\
\text { hukuman } \\
\text { pada } \\
\text { yang } \\
\text { bersalah }\end{array}$ & $\begin{array}{l}\text { Watak Lintang } \\
\text { (bintang) } \\
\text { Kuat } \\
\text { memegang } \\
\text { prinsip }\end{array}$ & $\begin{array}{l}\text { Laku Kartika } \\
\text { (bintang) } \\
\text { Percaya diri, } \\
\text { memegang } \\
\text { prinsip }\end{array}$ \\
\hline
\end{tabular}

Dalam tabel komparasi di atas kita melihat adanya perbedaan pada karya sastra tersebut dalam memaknai nilai-nilai kepemimpinan Astha Brata. Oleh karena itu, agar memudahkan kita dalam mendeskripsikan aktualisasi nilai Astha Brata pada manajemen kepemimpinan kepala sekolah SMA Negeri 19 Takengon. Perlu bagi kita untuk merumuskan makna operasional nilai Astha Brata.

Tabel 2. Definisi umum nilai Astha Brata

\section{No Nilai Kepemimpinan Makna Operasional}

1 Surya (Matahari) Pemimpin harus memiliki sifat etos kerja yang tinggi, dan juga sebagai pembimbing, mengutamakan musyawarah dalam setiap penyelesaian permasalahan. la juga menjadi inspirasi bagi setiap orang.

2 Wayu (Angin) Pemimpin harus memiliki sifat teliti yang tinggi, dan turun langsung sebagai pengawas untuk meninjau suatu kinerja.

3

Candra (Bulan)

$4 \quad$ Agni (Api)

$5 \quad$ Bumi (Prithiwi)

$6 \quad$ Indra (Hujan)

$7 \quad$ Waruna (Laut)
Pemimpin harus memiliki sifat periang dan penyayang. Dengan begitu pemimpin tersebut akan disayangi oleh setiap orang.

Pemimpin harus memiliki sifat semangat,dan harus berani memberi hukuman yang tegas kepada yang melanggar aturan.

Pemimpin harus memiliki rasa adil dalam memperlakukan setiap orang, dan juga memiliki sifat rendah hati.

Pemimpin harus memberi keuntungan untuk setiap orang. Artinya kehadiran sosok pemimpin harus memberikan hal yang positif.

Pemimpin harus berkharisma dan disegani, berani dalam 
menghadapi permasalahan apapun.

Pemimpin harus memegang teguh prinsip, merangkul setiap orang, dan tegas dalam memberikan perintah. Sanksi yang keras juga diberikan bagi yang melanggar aturan.

\section{Sejarah Singkat SMA Negeri 19 Takengon}

SMA Negeri 19 Takengon didirikan pada tahun 2012, sesuai dengan Surat Keputusan Pemerintah bernomor 421.3/1472012 tanggal 9 Juli 2012. Sekolah ini terletak di Desa Pantan Tengah, Kecamatan Rusip Antara Kabupaten Aceh Tengah, dan menjadi satu-satunya sekolah SMA di kecamatan tersebut. Kepala sekolahnya adalah Drs. Bahtiar (2012-2014). Cukup banyak kendala yang terjadi di lapangan pada awal sekolah ini berdiri. Mulai dari ketersediaan guru, tidak semua guru mau mengajar ke daerah yang cukup jauh dari Kota Takengon. Kemudian kurangnya minat sekolah bagi masyarakat setempat, hingga sarana dan prasarana pendukung pembelajaran yang sangat kurang. Menurut data pokok pendidikan SMA Negeri 19 Takengon, sekolah ini pada awal berdirinya hanya memiliki tiga ruang kelas dengan 20 peserta didik, dan 1 rombel.

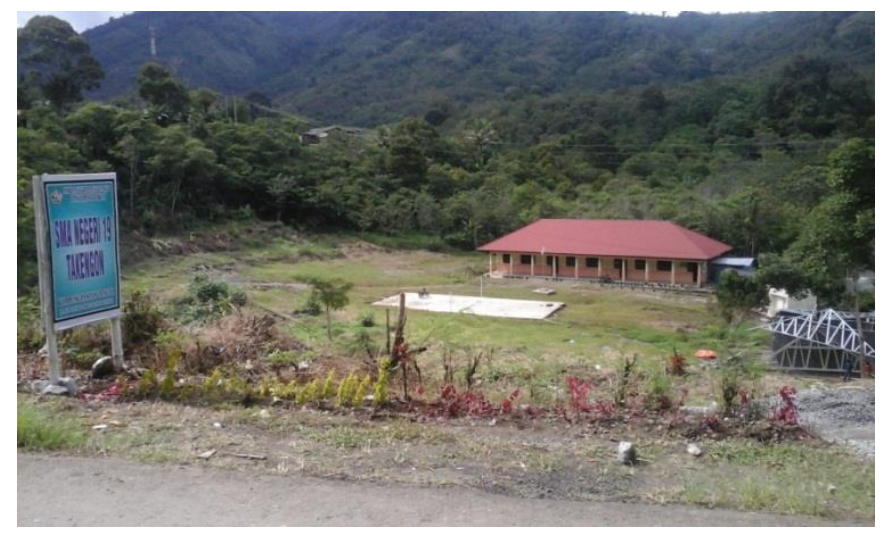

Gambar 1: Kondisi SMA Negeri 19 Tahun 2014 (sumber: Dok.Sekolah)

Memasuki tahun 2014 tidak banyak terjadi perubahan yang berarti pada sekolah ini. Pada tahun itu ruang kelas yang tersedia hanya sebanyak tiga ruangan, sedangkan ruangan guru, digabungkan dengan ruangan belajar peserta didik, dan hanya dipisahkan dengan sekat pembatas dari kayu triplek. Sehingga kerap kali, pembelajaran dan aktivitas kantor terganggu (Muhammad, 2021). Kondisi sekolah yang dikelilingi kebun kopi warga dan tanpa pagar sekolah, meyulitkan guru untuk mengawasi peserta didik pada saat jam istirahat. Namun kendala tersebut tidak menjadi halangan bagi guru-guru di sekolah tersebut untuk mendidik generasi bangsa.

SMA Negeri 19 Takengon mengalami perkembangan yang signifikan di bawah kepemimpinan Muhammad, S.Ag (2014-Sekarang). Sebagai kepala sekolah, ia kerap bersilahturahmi langsung ke rumah masyarakat sekitar, mendengar keluhan-keluhan mereka, dan berkordinasi dengan tokoh masyarakat setempat terkait pembelajaran di sekolah. Tidak ketinggalan dengan tokoh-tokoh pemangku kebijakan seperti Kepala Cabang Dinas Pendidikan Wilayah Aceh Tengah, Kepala Dinas Pendidikan Provinsi Aceh, juga tokoh-tokoh politik yang berasal dari Aceh Tengah, hingga Gubernur Aceh. Dari hasil hubungan yang baik tersebut, keluhan-keluhan para warga sekolah seperti, penambahan ruang belajar, dan fasilitas pendukung lainnya terjawab. Setiap tahunnya, Pemerintah Aceh aktif membangun fasilitas sekolah seperti, ruangan belajar, 
lapangan, bahkan bantuan komputer untuk pelaksanaan Ujian Nasional Berbasis Komputer (UN-BK).

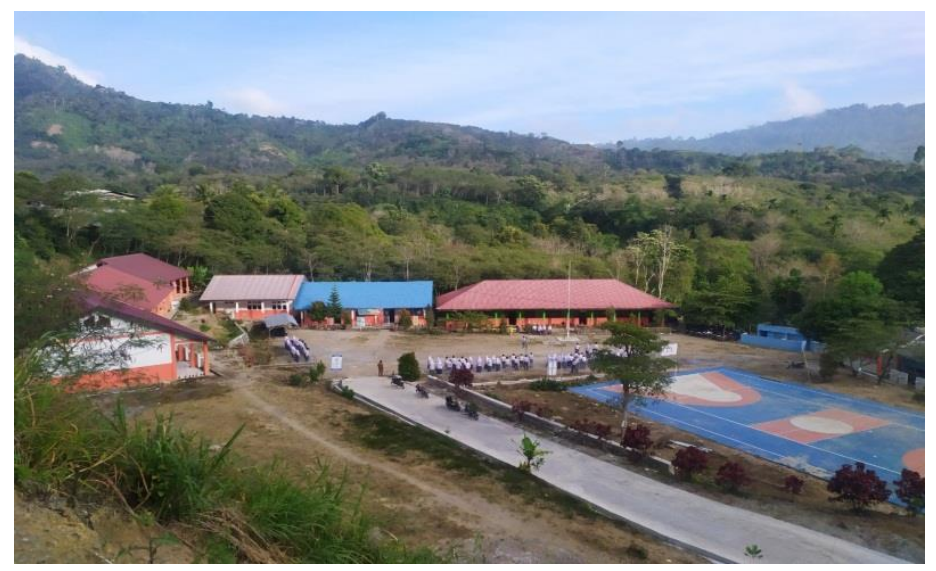

Gambar 2: SMA Negeri 19 Takengon pada tahun 2020 (Sumber: Dok. Sekolah)

Saat ini SMA Negeri 19 Takengon, memiliki peserta didik sebanyak 170 orang dengan jumlah rombel 8, dan satu kelas jauh di Desa Pameue, Kecamatan Rusip Antara, Aceh Tengah. Pembentukan kelas jauh tersebut tidak terlepas dari peran kepala sekolah, dan seluruh stakeholder Pemerintah Aceh, yang telah mendukung pembentukan kelas jauh tersebut. Sampai tahun 2021, Desa Pameue belum memiliki satupun SMA, sehingga banyak anak tidak dapat melanjutkan ke tingkat pendidikan SMA. Akibatnya anak-anak mengalami putus sekolah. Berangkat dari hal itu, Muhammad sebagai kepala sekolah mencetuskan ide tentang pembentukan kelas jauh SMA Negeri 19 Takengon, ide tersebut sudah dilayangkannya sejak tahun 2017, namun baru disetujui oleh Kepala Dinas Pendidikan Provinsi Aceh pada pertengahan tahun 2021, yang kini dijabat oleh Drs.Alhudri,M.M.

Di balik kemajuan sekolah yang signifikan. Permasalahan yang pelik seperti minat peserta didik untuk sekolah, masih terdapat hingga sekarang. Pada saat musim panen kopi tiba, ruang kelas seringkali kosong karena peserta didik memilih membantu orang tuanya memanen kopi, daripada pergi ke sekolah. Mayoritas orang tua peserta didik berprofesi sebagai petani-pekebun yang banyak menghabiskan waktunya di kebun dari pagi hingga sore, sehingga peran sentral orang tua dalam menjadi pendidik utama di rumah tidak terpenuhi. Ini juga menjadi permasalahan tersendiri dan berpengaruh terhadap perilaku peserta didik di sekolah. Pembelajaran literasi digital, sebagai langkah pembelajaran di era Revolusi Industri 4.0 juga tidak dapat berjalan maksimal. Hal ini disebakan di daerah tersebut sering terjadi pemadaman listrik, dibarengi dengan matinya sinyal internet.

\section{Aktualisasi Nilai Kepemimpinan Astha Brata}

Pada pembahasan ini, akan dideskripsikan bentuk aktualisasi nilai Astha Brata dalam manajemen kepemimpinan Kepala SMA Negeri 19 Takengon. Aktulisasi sifat kepemimpinan ini, di tinjau dari permasalahan yang terdapat pada SMA Negeri 19 Takengon dan bagaimana memecahkan permasalahan tersebut. Melalui analisis dokumentasi kegiatan dalam bentuk foto-foto, kemudian disimpulkan bentuk aktualiasi dari nilai kepemimpinan Astha Brata. 


\section{Sifat Surya (Matahari)}

Dalam tiga tahun terakhir, alumni SMA Negeri 19 Takengon sangat minim yang melanjutkan pendidikan ke tingkat perguruan tinggi. Meskipun bantuan pemerintah melalui KIP-K (Kartu Indonesia Pintar Kuliah) telah tersedia bagi peserta didik yang berprestasi dan kurang mampu. Oleh karena itu, kepala sekolah memberikan pengertian tentang pentingnya peserta didik melanjutkan pendidikan ke perguruan tinggi, dan juga bermusyawarah mengenai hambatan-hambatan yang dimiliki orang tua wali, untuk menyekolahkan anaknya ke tingkat perguruan tinggi.

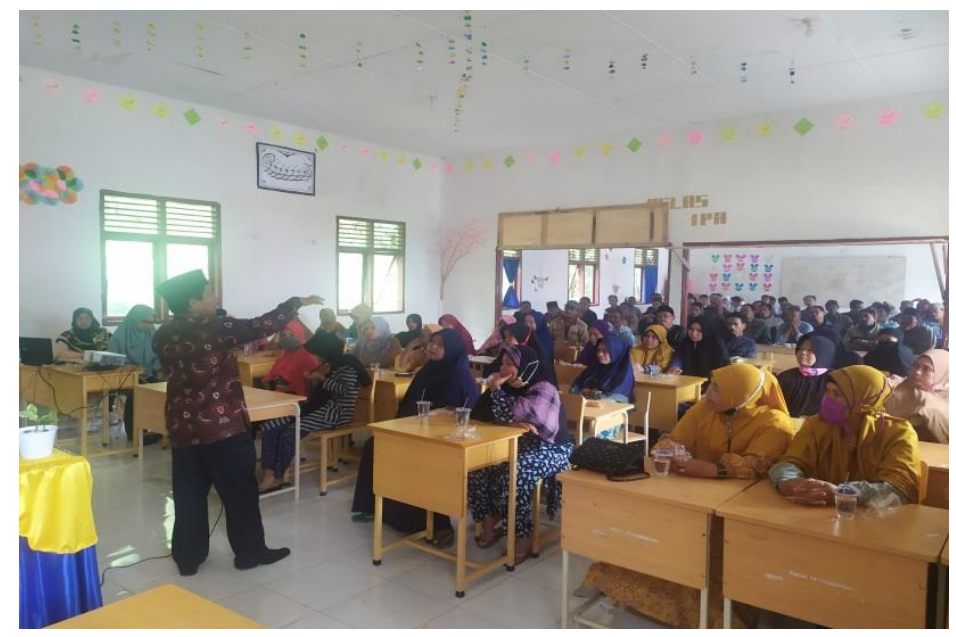

\section{Sifat Wayu (Angin)}

Gambar 3: Sosialisasi terhadap orang tua wali. (sumber. Dok Sekolah)

Sifat kepemimpinan ini, dapat dilihat ketika terjadi bencana tanah longsor di badan jalan sekolah. Untuk memastikan agar para peserta didik dan guru, dapat memasuki sekolah, kepala sekolah turun langsung untuk membersihkan jalan menuju ke sekolah. Hal ini bertujuan agar proses pembelajaran tetap berjalan dengan sebagaimana mestinya.

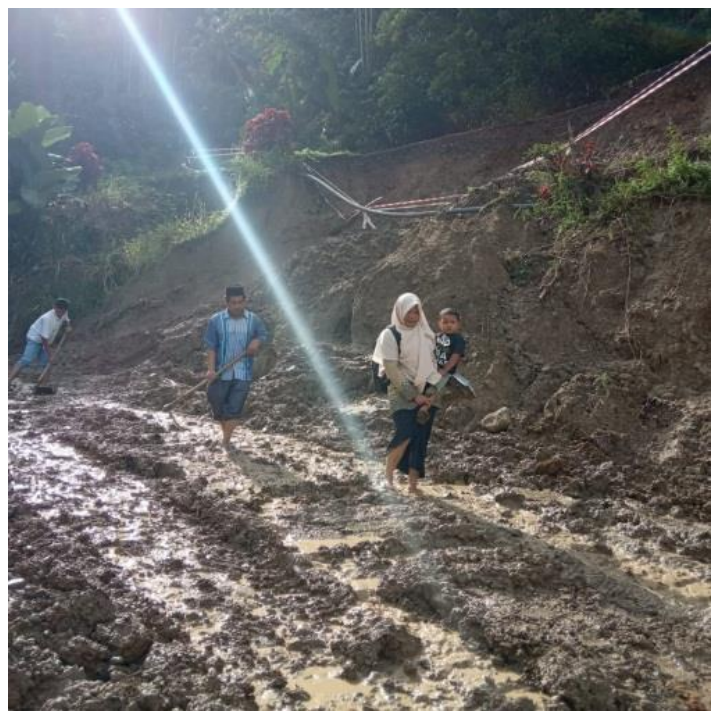

Gambar 4: Kepala Sekolah sedang meratakan jalan yang longsor (Sumber. Dok Sekolah) 


\section{Sifat Candra (Bulan)}

Salah satu tipe pemimpin yang baik, dia akan selalu disayangi dan dirindukan setiap orang. Kepala sekolah menerima kunjungan para alumni yang telah melanjutkan pendidikan ke perguruan tinggi di Universitas Al-Muslim. Mereka menganggap kepala sekolah seperti seorang ayah sendiri, yang selalu aktif menjalin komunikasi dan memantau mereka dalam perkuliahan.

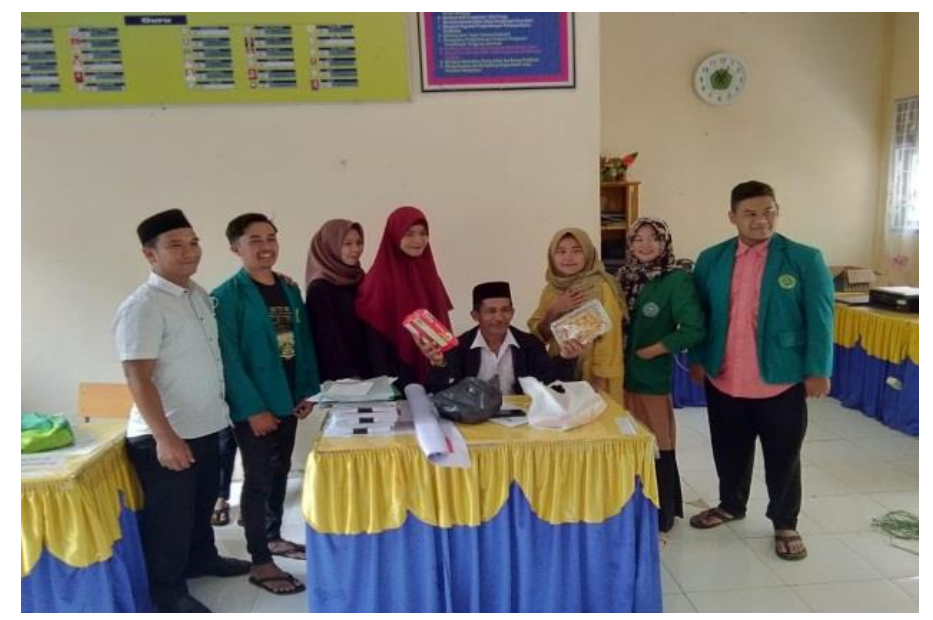

Gambar 5: Kepala Sekolah dan alumni (Sumber. Dok. Sekolah)

\section{Sifat Agni (Api)}

Keberanian langkah yang diambil dan semangat dalam membangun, terlihat dari komitmen kepala sekolah untuk membuka kelas jauh di Desa Pameue, yang sampai tahun 2021 belum memiliki sekolah menengah tingkat atas yang berstatus negeri.
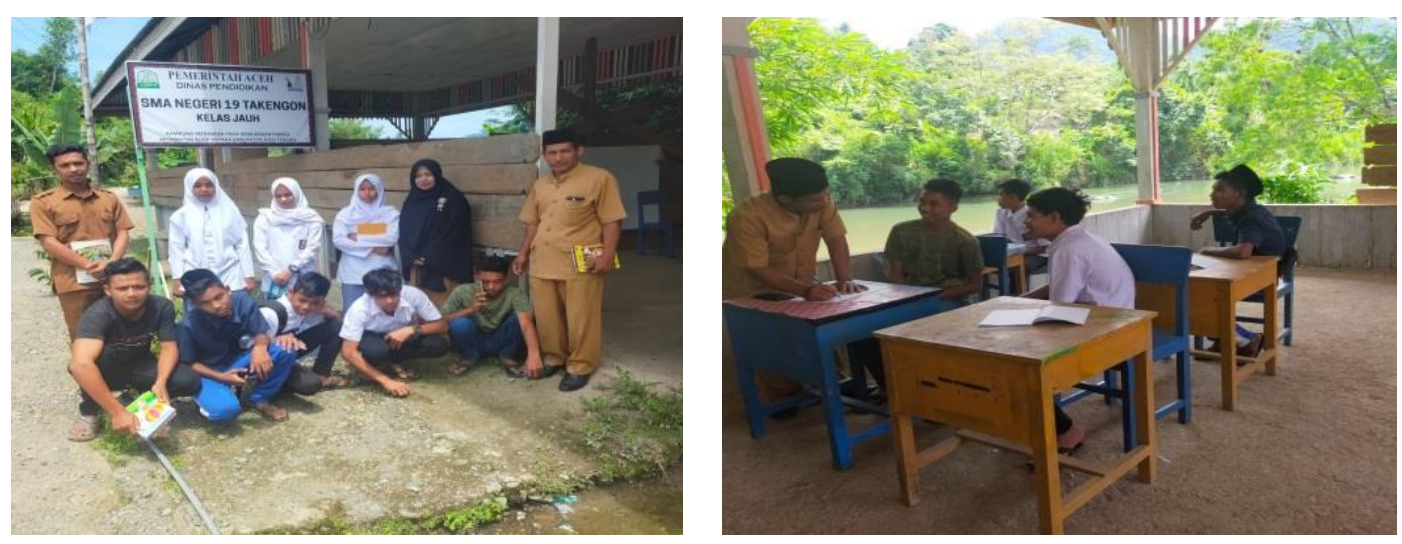

Gambar 6: Kondisi kelas jauh SMAN Negeri 19 Takengon

(Sumber: Dok. Sekolah) 


\section{Sifat Prithiwi (Bumi)}

Faktor ekonomi menyebabkan tidak semua orang tua wali di Desa Pameue menyekolahkan anaknya ke kelas jauh yang telah dibuka. Untuk itu kepala sekolah mengunjungi rumah-rumah masyarakat, dan meyakinkan orang tua wali bahwa anak mereka wajib untuk mendapatkan pendidikan.

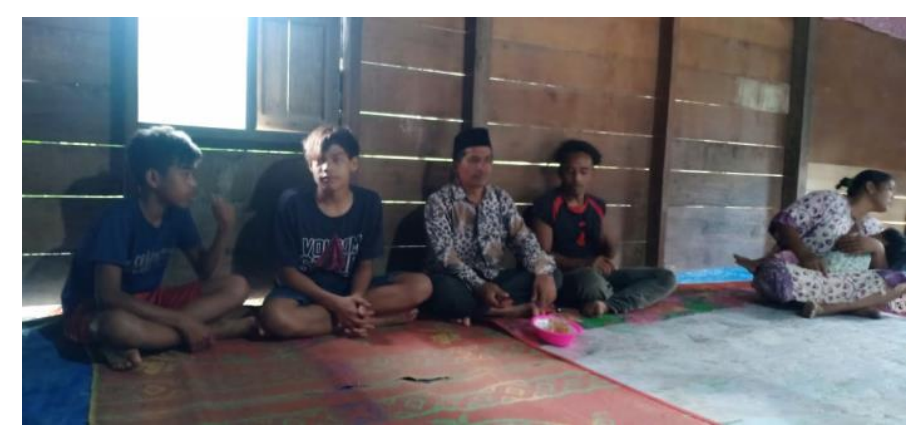

Gambar 7: Kunjungan kepala sekolah di Desa Pameue (Sumber. Dok.Sekolah)

\section{Sifat Indra (Hujan)}

Karena keadaan ekonomi, banyak peserta didik dari kelas jauh yang tidak pergi ke sekolah untuk membantu orang tuanya yang bekerja sebagai petani-pekebun. Oleh karena itu, kepala sekolah sedikit meringankan beban mereka dengan memberi bantuan buku tulis, agar mereka tetap ke sekolah.

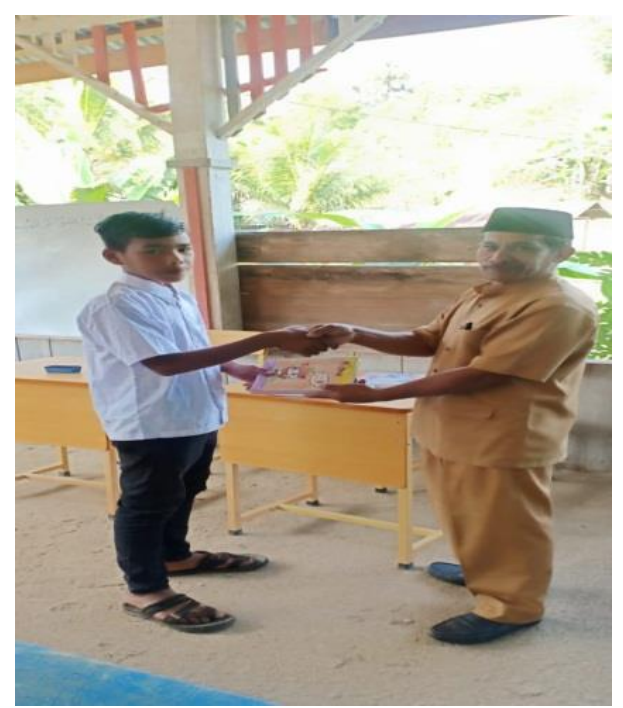

Gambar 8: Bantuan buku tulis yang diberikan oleh kepala sekolah (Sumber. Dok.Sekolah)

\section{Waruna (Laut)}

Dalam dua pekan terakhir, Pemerintah Aceh sedang gencar-gencarnya melakukan vaksinasi untuk peserta didik. Banyak tanggapan negatif tentang vaksin, sehingga di beberapa sekolah orang tua tidak mengizinkan anaknya untuk vaksinasi. Oleh karena itu, kepala sekolah melakukan kordinasi dengan orang tua wali menyertakan muspika setempat agar vaksinasi dapat berjalan lancar. 


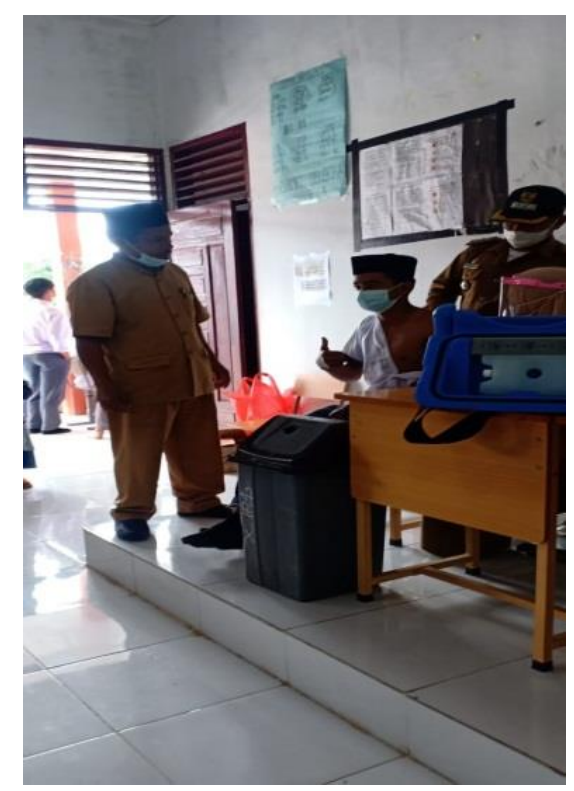

Gambar 9: Vaksinasi bagi peserta didik SMA Negeri 19 Takengon (Sumber. Dok. Sekolah)

\section{Sifat Yama (Maut)}

Kepala sekolah sebagai pemimpin di sekolah, harus merangkul seluruh warga sekolah. Kepala sekolah kerap melakukan diskusi dengan para guru, mengenai proses pembelajaran dan kendalanya di lapangan. Hasil diskusi tersebut, biasa berupa kebijakan yang harus dilaksanakan oleh guru. Dalam rapat rutin kepala sekolah juga melakukan evaluasi guru-guru dalam mengajar di kelas.

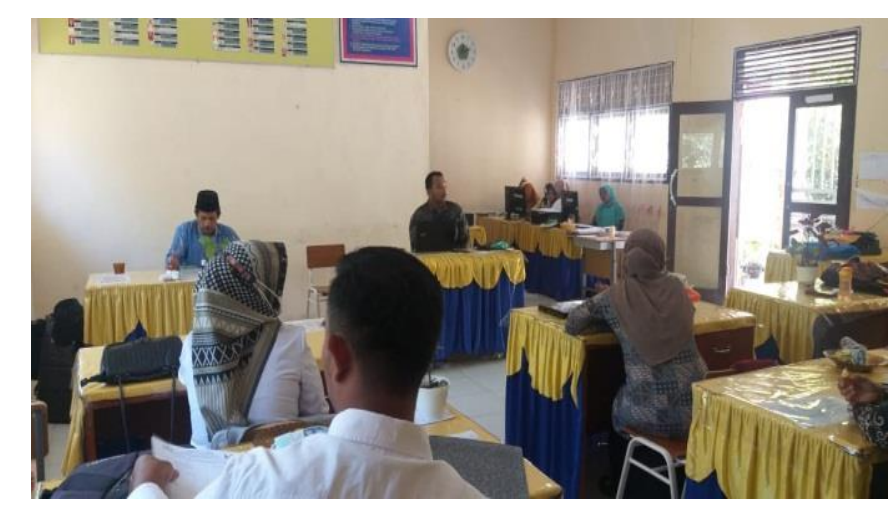

Gambar 10: Kepala sekolah memberi arahan dalam Rapat rutin dewan guru (Sumber Dok. Sekolah)

\section{SIMPULAN}

Delapan nilai kepemimpinan Astha Brata dirumuskan dari sifat-sifat dewa dalam tradisi hindu yang terdapat di alam seperti sifat Surya (Matahari), Wayu (Angin), Candra (Bulan), Agni (Api), Prtihiwi (Bumi), Indra (Hujan), Waruna (Laut), Yama (Maut). 
SHEs: Conference Series 5 (1) (2022) 24- 35

Deskripsi yang dilakukan dari berbagai dokumentasi berupa foto-foto. Nilai kepemimpinan Astha Brata telah diaktualisasikan pada manajemen kepemimpinan Kepala SMA Negeri 19 Takengon. Aktualisasi nilai kepemimpinan tersebut, sangat membantu kepala sekolah dalam mengatasi kendala-kendala yang terjadi pada penyelenggaraan sekolah.

\section{DAFTAR PUSTAKA}

Adisastra, S.I dan Made,N.D.A.Y. (2021). "Relevansi Asta Brata Dalam Kepemimpinan Masa Kini”. Swara Vidya, 1(1), 1-13

Anggito, A dan Setiawan, J. (2018). Metode Penelitian Kualitatif. Jawa Barat: CV Jejak Aryawan,W.I. (2021). "Penerapan Kepemimpinan Asta Brata dalam Pendidikan dari Sudut Pandang Teori Konflik". Jurnal IImiah IImu Sosial, 7(1), 56-66

As'ad, M.,Anggoro, J.W.,Virdanianty, M. (2011). "Studi Eksplorasi Konstrak Kepemimpinan Model Jawa: Asta Brata". Jurnal Psikologi, 38 (2), 228-239

Bali, K. (2019). "Menggagas Kepemimpinan Berlandaskan Ajaran Asta Brata dan Etos Kerja Terhadap Kinerja Guru”. Purwadita: Jurnal Agama dan Budaya, 3(2), 55-64

Endraswara, S. (2013). Falsafah Kepemimpinan Jawa. Yogyakarta: Narasi.

Gaol, L.T.N. (2020). 'Teori kepemimpinan: Kajian Dari Genetika Sampai Skill”. Universitas Muhamadiyah Surakarta, 5(2),158-173

Raco, J.R. (2010). Metode Penelitian Kualitatif. Jakarta: PT Grasindo

Sastramayani dan Badarwan. (2019). "Kepemimpinan Krisis dalam Pengelolaan Sekolah". Shautut Tarbiyah, 25(2), 181-201

Silawati, W.N. 2021. Delapan Sifat Pemimpin Ideal:Kajian Perspektif Agama Hindu. Badung: Nilacakra

Sudarmiati, N. (2020). " Landasan Ajaran Asta Brata Dalam Kepemimpinan Kepala Sekolah Di SMA N 7 Luwu Timur”. Widyalaya: Jurnal IImu Pendidikan, 1(2), 221232

Suyami. (2008). Konsep Kepemimpinan Jawa dalam Ajaran Sastra Cetha dan Asta Brata. Yogyakarta: Kepel Press 